\title{
Candida albicans SUR7 contributes to secretion, biofilm formation, and macrophage killing
}

Stella M Bernardo 1,2 and Samuel A Lee*1,2

\begin{abstract}
Background: Candida albicans SUR7 has been shown to be required for plasma membrane organization and cell wall synthesis, but its role in virulence is not known. Using a bioinformatics strategy, we previously identified several novel putative secretion pathway proteins potentially involved in virulence, including the C. albicans homolog of the Saccharomyces cerevisiae endocytosis-related protein Sur7p. We therefore generated a C. albicans sur7 $\triangle$ null mutant and examined its contribution to key virulence attributes.

Results: Structurally, the C. albicans sur $7 \triangle$ mutant was impaired in response to filamentation-inducing conditions, and formed aberrant hyphae with extensive accumulation of plasma membrane-derived structures within the cell. Absence of SUR7 resulted in a temperature-sensitive growth defect at high temperatures $\left(42^{\circ} \mathrm{C}\right)$, which was partially rescued by addition of $\mathrm{NaCl}$. We next examined the role of the SUR7 paralog C. albicans FMP45 in this temperaturesensitive phenotype. Analysis of C. albicans Fmp45p-GFP demonstrated co-localization of Fmp45p with Sur7p and increased fluorescence in the plasma membrane in the presence of high salt. We next focused on key virulence-related phenotypes. The C. albicans sur $\triangle \triangle$ null mutant exhibited secretory defects: reduced lipase secretion, and increased levels of secreted Sap2p. The null mutant was hyper-susceptible to sub-inhibitory concentrations of caspofungin, but not amphotericin B and 5-fluorocytosine. Functionally, the sur $7 \triangle$ mutant demonstrated increased adhesion to polystyrene and of note, was markedly defective in biofilm formation. In an in vitro macrophage model of virulence, the sur $\triangle \triangle$ mutant was impaired in macrophage killing.

Conclusions: Plasma membrane and cell wall organization are important for cell morphology, and alterations of these structures contributed to impairment of several key virulence-associated phenotypes in the C. albicans sur $7 \triangle$ mutant.
\end{abstract}

\section{Background}

C. albicans SUR7 shares $44 \%$ identity and $65 \%$ similarity with S. cerevisiae SUR7. S. cerevisiae SUR7 encodes a predicted integral membrane protein with an $\mathrm{N}$-terminal signal sequence and four transmembrane domains, and is a member of a family of proteins that also includes Yn1194p, Ydl222p, and Ylr414cp [1,2]. Sur7p localizes to large, immobile, stable cortical patches on the plasma membrane, termed "eisosomes" which mark sites of endocytosis [3,4]. Deletion of S. cerevisiae SUR7 resulted in a strain with a defect in sporulation and altered plasma membrane sphingolipid content [4].

\footnotetext{
*Correspondence: SamALee@salud.unm.edu

1 Section of Infectious Diseases, New Mexico Veterans Healthcare System, Albuquerque, NM, USA

Full list of author information is available at the end of the article
}

Alvarez and Konopka [5] identified C. albicans Sur7p in a detergent-resistant fraction of the plasma membrane in a proteomics study on $N$-acetylglucosamine-induced proteins. Recently, they generated a C. albicans sur7 $\mathrm{k}$ knockout mutant which is characterized by aberrant cell wall organization [2]. Specifically, lack of SUR7 in C. albicans results in mislocalization of actin and septin, and abnormal cell wall material protruding into and forming structures within the cytoplasm. However, from a phenotypic standpoint, little is known regarding the role of C. albicans SUR7 in pathogenesis.

A number of C. albicans virulence-related secreted proteins that remain associated with the plasma membrane or cell wall have been identified, including the outer mannoprotein Hwp1p [6], adhesins encoded by the $A L S$ family of genes [7], and membrane proteins encoded by the $\mathrm{pH}$-responsive genes PHR1 and PHR2 [8-11]. 
However, a genome-wide understanding of Candida secretory pathway proteins and virulence is still limited. Previously, we took advantage of SignalP v2.0 $[12,13]$ and a series of additional validated predictive algorithms to define a computational secretome of $C$. albicans from its entire genome [14]. In addition to identifying putative soluble secretory proteins, we also identified a number of putative and known membrane and cell-wall associated proteins [14]. We next compared these databases with published genome-wide expression profiling data to identify candidate virulence-related genes. Fradin et al. [15] performed genomic expression profiling in C. albicans exposed in vitro to blood and in vivo during infection in a standard mouse model of disseminated candidiasis and identified groups of genes highly expressed under these conditions. When compared with the dataset of predicted secretion pathway ORFs, a number of virulencerelated genes were concordant, including Hwplp and the Als family of adhesins [6,7], Phr1p [8], Sap9p [16], Sod5p $[17,18]$, and Sun41p [19-21]. Thus, we identified known soluble secreted and membrane-associated secretion pathway proteins important for virulence, supporting our approach as a method to identify candidate virulencerelated genes.

We also identified orf19.3414, which is predicted to encode a secretion pathway protein homologous to the $S$. cerevisiae endocytosis-related gene SUR7 [1]. As we independently identified C. albicans SUR7 in our screen for candidate virulence-related genes, we used a reverse genetic approach to investigate the role of $C$. albicans SUR7 in attributes related to virulence in order to define its role in pathogenesis.

\section{Results}

\section{The temperature sensitive growth defect of the Candida} albicans sur $7 \Delta$ mutant is partially rescued by high salt

We generated a $C$. albicans sur $7 \Delta$ homozygous null mutant by PCR-mediated gene disruption [22,23], SMB3$\mathrm{H}$, followed by construction of an isogenic complemented strain, SMB3-R (Table 1). Before proceeding with phenotypic characterizations of the sur7 $\Delta$ null mutant, we assessed the growth of each strain by calculating doubling times. Growth curves and the resulting doubling times are presented in Fig. 1 and Table 2, respectively. In rich medium, there was no statistically significant difference ( $p>0.05$ ) between the calculated doubling times of the $C$. albicans sur7D mutant, prototrophic control strain DAY185, and the isogenic complemented strain (Fig. 1A and Table 2). Growth in response to high osmotic stress $(1.0 \mathrm{M} \mathrm{NaCl}$ or $2.5 \mathrm{M}$ glycerol) was the same as that of the control strains when incubated at either 30 or $37^{\circ} \mathrm{C}$ (data not shown). Interestingly, when incubated at $42^{\circ} \mathrm{C}$, growth of the sur7 $\Delta$ null mutant strain was markedly impaired, in contrast to the control and SUR7 comple- mented strains (Fig. 1B). The sur7 $\Delta$ null mutant grew at one-third the rate of the wild-type control strains (Table 2). Unexpectedly, the $\operatorname{sur} 7 \Delta$ null mutant's inability to grow at $42^{\circ} \mathrm{C}$ was partially rescued when grown under conditions of high salt (1.0 M NaCl; Fig. 1C); differences in doubling time compared to the control strains were statistically significant $(\mathrm{p}<0.001)$.

\section{C. albicans Fmp45p-GFP fluorescence intensity increases in the presence of high salt and temperature}

In S. cerevisiae, transcript levels of the SUR7 paralog YNL194 is increased in the presence of high salt [24]. Expression of the Ynl194p-GFP fusion protein under its native promoter shifted from barely detectable fluorescence levels to highly detectable levels with the addition of high salt, and the gene product was found to co-localize with S. cerevisiae Sur7p [4]. There is only one closely related paralog of $\mathrm{Ca}$ Sur7p in C. albicans, $\mathrm{Ca}$ Fmp45p (orf19.6489), which shares $31 \%$ identity and $45 \%$ similarity. According to predictions using TMHMM http:// www.cbs.dtu.dk/services/TMHMM/, Fmp45p has 4 transmembrane domains similar to Sur7p defined by amino acids 7-29; 106-128; 135-157; 186-208, and 7-29; 104-126; 139-161; 183-205, respectively. These results are similar to data presented by Alvarez et al. [2] who also noted the presence of a conserved Cys-containing motif in C. albicans Fmp45p similar to the consensus sequence that is characteristic of members of the claudin family of proteins. To explore the functional relation between $C$. albicans SUR7 and FMP45, we created a double-fluorescent labelled strain, SUR7-YFP FMP45-GFP, whose expression of both fusion proteins remain under the control of their native promoters. While the fluorescence emission overlap of YFP and GFP makes it impossible to separate them using conventional epifluorescence imaging, the Nuance ${ }^{\mathrm{Tm}}$ Multispectral Imaging System (CRi) can distinguish the spectra of the YFP- and GFP-tagged proteins, and produce separate images of Sur7p-YFP and Fmp45p-GFP from the single SUR7-YFP FMP45-GFP strain. The merged fluorescence images indicate that Fmp45p co-localizes in a punctate pattern with the plasma membrane-bound protein Sur7p (Fig. 2A). These results are similar to that observed in S. cerevisiae [4]. We thus hypothesized that under these specific growth conditions (high temperature and salt), the C. albicans para$\log$ FMP45 may be contributing to a compensatory response to high salt.

To test this hypothesis, we created strains B-FMP45gfp and s $\Delta$-FMP45gfp expressing the Fmp45p-GFP fusion protein in both wild-type and sur $7 \Delta$ null backgrounds, respectively (Table 1). In the wild-type background, Fmp45p-GFP fluorescence intensity is very low, and appears to display a punctate pattern of plasma membrane localization (Fig. 2B, panel I). In the presence of 
Table 1: Candida albicans strains used in this study.

\begin{tabular}{|c|c|c|c|}
\hline Strain & Parent & Relevant genotype & Source \\
\hline DAY185 & & $\begin{array}{l}\text { ura3 ::Aimm434/ura3 ::Aimm434 his 1::hisG/HIS1::his 1::hisG arg4::hisG/ } \\
\text { ARG4::URA3::arg4::hisG SUR7/SUR7 }\end{array}$ & [48] \\
\hline BWP17 & & ura3 /ura3 arg4 /arg4 his /his1 SUR7/SUR7 FMP45/FM45 & [22] \\
\hline SMB2 & BWP17 & ura3 /ura3 arg4 /arg4 his /his1 SUR7/sur7 ::dpl200-URA3-dpl200 & This study \\
\hline SMB3 & SMB2 & $\begin{array}{l}\text { ura3 /ura3 arg4 /arg4 his /his1 sur7 ::dpl200-URA3-dpl200/ } \\
\text { sur7 ::ARG4 }\end{array}$ & This study \\
\hline SMB3-H & SMB3 & $\begin{array}{l}\text { ura3 /ura3 arg4 /arg4 his /his1 HIS1 } \\
\text { sur7 ::dpl200-URA3-dp/200/sur7 :: ARG4 }\end{array}$ & This study \\
\hline SMB3-R & SMB3 & $\begin{array}{l}\text { ura3 /ura3 arg4 /arg4 his /his1 HIS1::SUR7 } \\
\text { sur7 ::dpl200-URA3-dpl200/sur7 :: ARG4 }\end{array}$ & This study \\
\hline B-FMP45gfp & BWP17 & ura3 /ura3 arg4 /arg4 his /his1 SUR7/SUR7FMP45/FM45-GFP-HIS1 & This study \\
\hline s -FMP45gfp & SMB3 & $\begin{array}{l}\text { ura3 /ura3 arg4 /arg4 his /his1 FMP45/FM45-GFP-HIS1 } \\
\text { sur7 ::dpl200-URA3-dpl200/sur7 :: ARG4 }\end{array}$ & This study \\
\hline SUR7-YFP & BWP17 & ura3 /ura3 arg4 /arg4 his/his1 FMP45/FM45 SUR7/SUR7-YFP-HIS1 & This study \\
\hline SUR7-GFP & BWP17 & ura3 /ura3 arg4 /arg4 his /his1 FMP45/FM45 SUR7/SUR7-GFP-HIS1 & This study \\
\hline SUR7-YFP FMP45-GFP & SUR7-YFP & $\begin{array}{l}\text { ura3 /ura3 arg4 /arg4 his /his1 SUR7/SUR7-YFP-HIS1 FMP45/ } \\
\text { FM45-GFP-URA3 }\end{array}$ & This study \\
\hline
\end{tabular}

high salt, Fmp45p fluorescence intensity in the $S U R 7^{+}$ background is increased (Fig. 2B, panel III). In the $\operatorname{sur} 7 \Delta$ null background, the fluorescence pattern of Fmp45pGFP is clearly punctate, similar to the localization of Sur7p, and in the absence of salt an increase in Fmp45pGFP fluorescence is readily observed (Fig. 2B, panel II). In the presence of high salt $(1.0 \mathrm{M} \mathrm{NaCl})$, Fmp45p-GFP fluorescence greatly increased in the $\operatorname{sur} 7 \Delta$ background and maintained the punctate pattern that is typical of Sur7p localization (Fig. 2B, panel IV). Using Image J software analysis, we quantified the relative fluorescence intensity of all major points around a given cell. The median intensity of each cell with a wild-type (without and with salt) and sur7 $\Delta$ null (without and with salt) background was 212, 279, 491, and 1040, respectively. These measurements are in agreement with visual observation of the images obtained (Fig. 2B). The co-localization of Fmp45p and Sur7p and the increase in fluorescence intensity of Fmp45p-GFP in the presence of $1 \mathrm{M} \mathrm{NaCl}$ together suggest that Fmp45p may play a role in tolerance of high salt in the absence of $C$. albicans Sur7p.
The Candida albicans sur $7 \Delta$ mutant is defective in tolerance to cell wall stress and antifungal agents targeting cell wall components

Next we tested growth in the presence of sub-inhibitory concentrations of several different classes of antifungal agents at 30 and $37^{\circ} \mathrm{C}$. No difference was seen in growth in the presence of amphotericin B or 5-fluorocytosine (data not shown). However, the $C$. albicans sur $7 \Delta$ mutant was more susceptible to sub-inhibitory concentrations of caspofungin (CAS at $0.25 \mu \mathrm{g} / \mathrm{ml}$; data not shown). We further investigated cell wall integrity in the $\operatorname{sur} 7 \Delta$ null mutant using a number of cell wall perturbing agents. Serial dilutions of each strain were spotted onto YPD medium containing various concentrations of CAS, SDS, Congo Red, and Calcofluor White. In the absence of SUR7 the organism was highly sensitive to each compound tested (Fig. 3). Furthermore, a modest gene dosage effect was suggested, as the degree of sensitivity of the SUR7-complemented strain was intermediate between that of the wild-type and sur $7 \Delta$ strains. When tested on the same media, the heterozygous mutant strain (SMB2) 
Table 2: Calculated doubling times of C. albicans strains under different conditions of growth.

\begin{tabular}{|c|c|c|c|}
\hline \multirow[b]{2}{*}{ Growth conditions } & \multicolumn{3}{|c|}{ Doubling time of each strain (hours) } \\
\hline & $\begin{array}{l}\text { Wild-type } \\
\text { (DAY185) }\end{array}$ & $\begin{array}{c}\text { sur7 } \\
\text { (SMB3-H) }\end{array}$ & $\begin{array}{c}\text { sur7 + SUR7 } \\
\text { (SMB3-R) }\end{array}$ \\
\hline $30^{\circ} \mathrm{C}, \mathrm{CSM}(\mathrm{p}>0.05)$ & $2.244 \pm 0.070$ & $2.199 \pm 0.016$ & $2.168 \pm 0.034$ \\
\hline $42^{\circ} \mathrm{C}, \operatorname{CSM}\left({ }^{*} \mathrm{p}<0.0001\right)$ & $3.645 \pm 0.066$ & $11.08 \pm 0.122 *$ & $3.560 \pm 0.055$ \\
\hline $\begin{array}{l}42^{\circ} \mathrm{C}, \mathrm{CSM}+1 \mathrm{M} \mathrm{NaCl}\left({ }^{*} p<\right. \\
0.001)\end{array}$ & $3.145 \pm 0.119$ & $3.374 \pm 0.072 *$ & $3.000 \pm 0.036$ \\
\hline
\end{tabular}

* indicates statistical significance of sur7 compared to wild-type and SUR7 complemented strains.

exhibited the same degree of sensitivity to cell wall perturbing agents as the SUR7 complemented strain (data not shown).

Taken together, these initial studies on the $\operatorname{sur} 7 \Delta$ mutant indicate an overall defect in cell wall structure, and consequent defects in the ability of the sur $7 \Delta$ mutant to tolerate specific stresses related to cell wall function. We next focused on studying the implications of this defective structure on factors that contribute to virulence, including adhesion, filamentation, protease secretion, and biofilm formation.

The $C$. albicans sur7 $\Delta$ mutant has an abnormal response to induction of filamentation and hyphal cells are markedly defective in plasma membrane structure

An important virulence attribute in C. albicans is the ability to switch between yeast, pseudohyphal, and filamentous forms [25-27]. When spotted onto M199 agar, hyphal structures were formed from each colony (Fig. 4A). However, the extent of filamentation was reduced in the sur7 $\Delta$ null mutant compared to DAY185 and the SUR7 complemented strain. Similar results were observed when grown on Spider agar medium at $37^{\circ} \mathrm{C}$ (Fig. 4A). When BSA agar plates were incubated for an extended period of time, filamentous structures emerged from the edge of each colony except in the $\operatorname{sur} 7 \Delta$ null mutant (Fig. 4A). This reduced filamentation in response to inducing conditions was also seen on solid media containing fetal calf serum (Fig. 4A). In liquid media (YPD supplemented with $10 \%$ FCS, high glucose D-MEM with $10 \%$ FCS, or RPMI-1640), time of germination and the extent of filament elongation of the C. albicans sur7 $\Delta$ mutant were grossly similar to the wild-type and SUR7 complemented strains (data not shown). However, when grown in weak hyphal-inducing liquid Spider medium, a

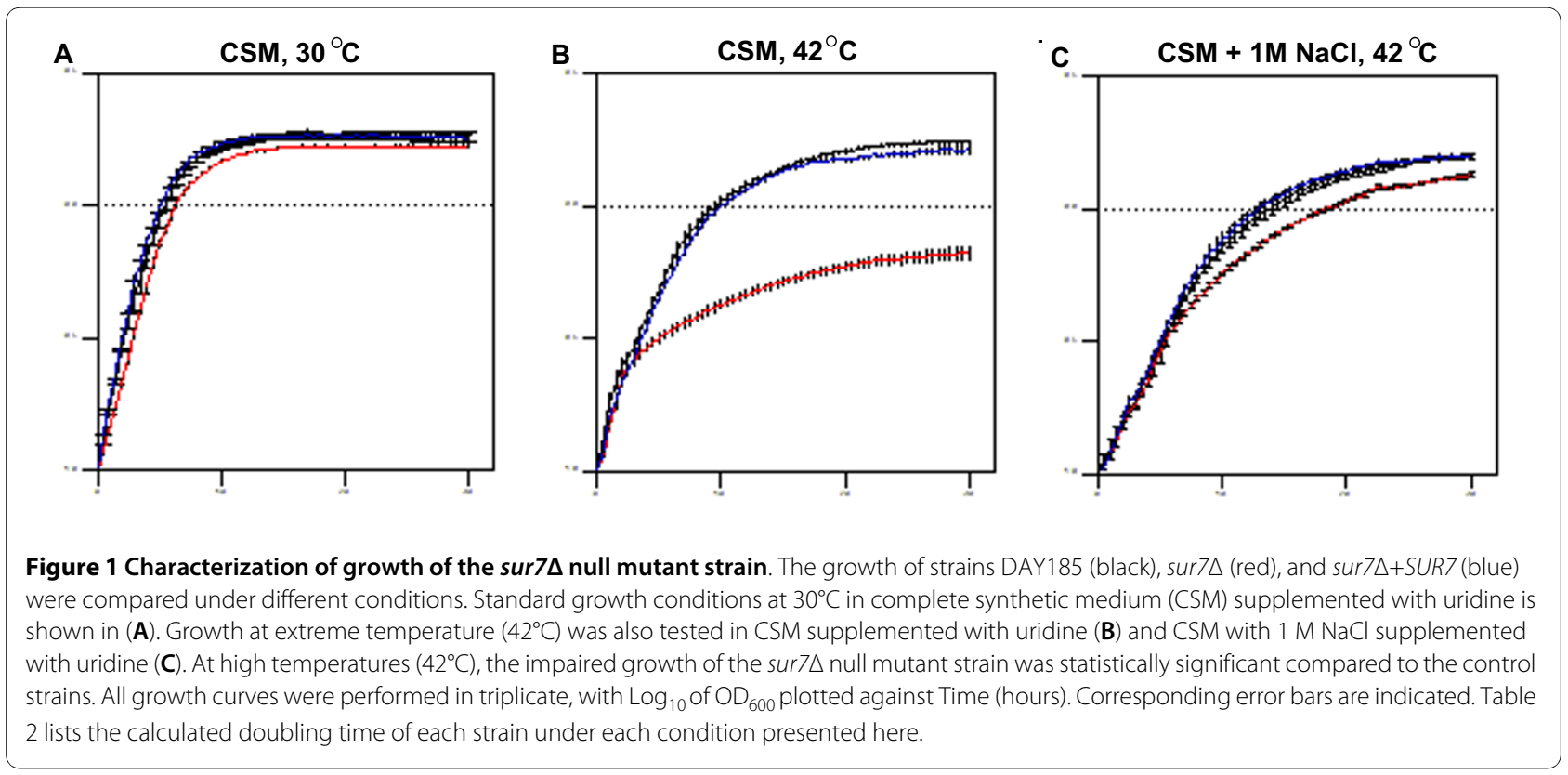




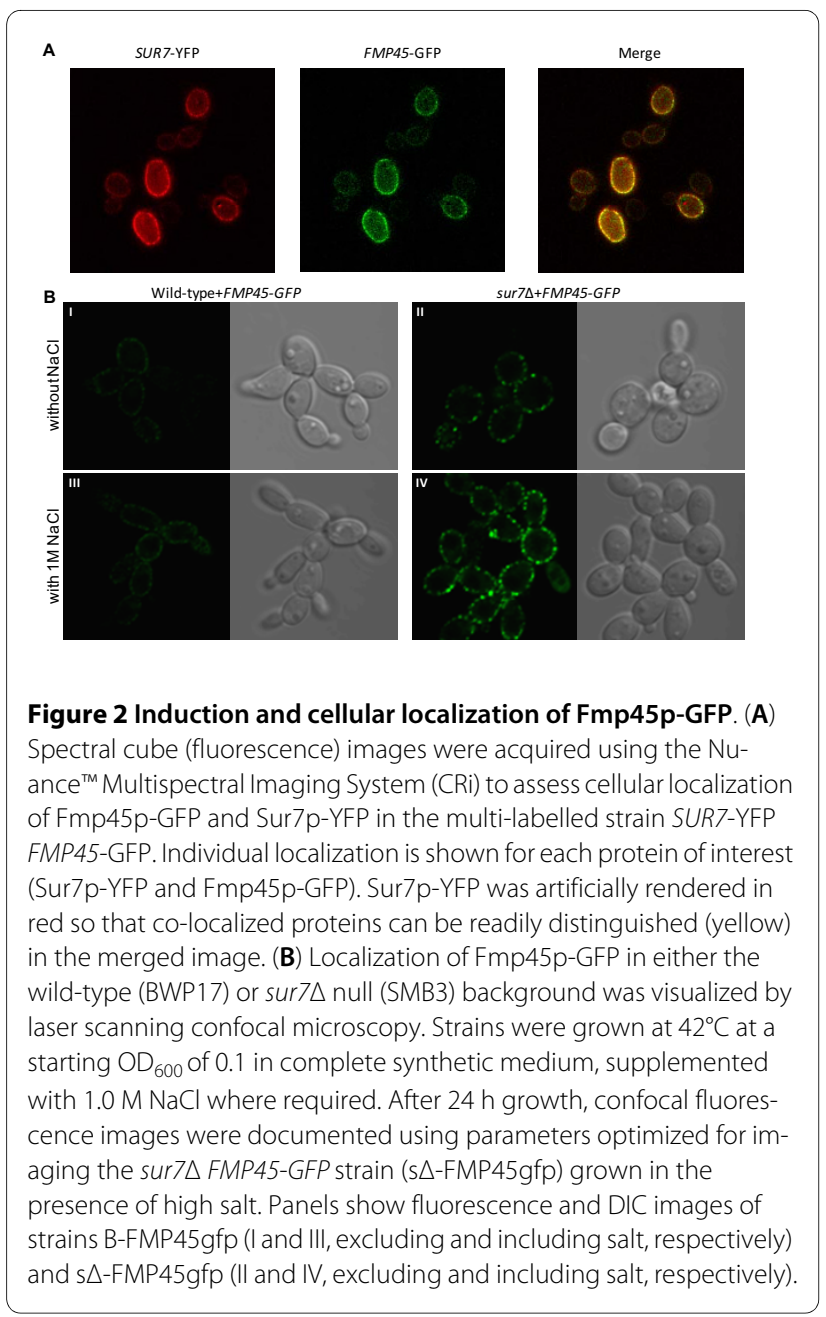

population of yeast cells and hyphae with aberrant morphology and branching was observed (Fig. 4B).

Next, structures of the filamentous form were compared using light microscopy. After 24 hours of growth, the wild-type (DAY185; Table 1) and SUR7 complemented strains produced mature, elongated hyphal cells with clear septa, whereas the sur $7 \Delta$ null mutant produced irregularly shaped hyphae with obvious intracellular invaginations (Fig. 5A). Thin-section electron microscopy demonstrated subcellular structures in the filaments formed by the sur $7 \Delta$ null mutant strain (Fig. 5B) which, as in the yeast form cells (presented in the next section), are likely related to the plasma membrane based on subcellular appearance.

\section{C. albicans sur7 $\Delta$ mutant hyphal cells are defective in endocytosis}

S. cerevisiae Sur7p is a component of eisosomes which mark sites of endocytosis in the plasma membrane [3]. Sur7p is localized to the plasma membrane in the filamentous form of $C$. albicans in a punctate pattern (Fig. $6 \mathrm{~A})$, similar to that observed in the yeast form, suggesting

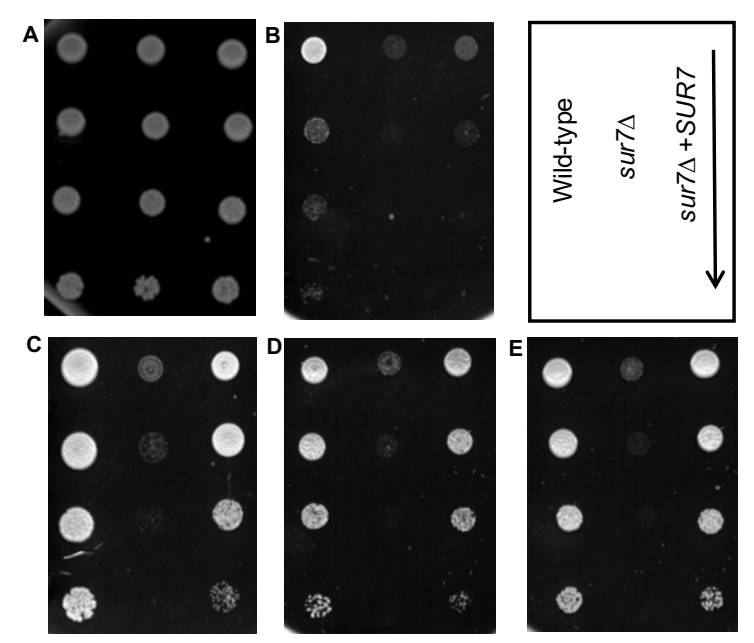

Figure 3 Cell wall defects of the sur $7 \Delta$ null mutant. Serial dilutions of overnight cultures were spotted onto different agar media and incubated for 2 days at $30^{\circ} \mathrm{C}$. Strains are indicated in the top right diagram with an arrow signifying decreasing cell densities $\left(1 \times 10^{7}, 2 \times\right.$ $10^{6}, 4 \times 10^{5}, 8 \times 10^{4}$ and cells $\mathrm{ml}^{-1}$ ) of the strains spotted onto each plate. Normal growth on YPD medium is shown in (A). YPD medium containing cell wall perturbing agents such as (B) $0.1 \mathrm{\mu g} \mathrm{ml}^{-1}$ caspofungin, (C) $0.02 \%$ SDS, (D) $200 \mu \mathrm{g} / \mathrm{ml}$ Congo Red, and (E) $50 \mathrm{\mu g} \mathrm{ml}^{-1}$ Calcofluor White are shown.

retention of its endocytic role in hyphae. Thus, to examine the role of the C. albicans Sur7p in endocytosis in filamentous cells, we used the lipophilic membrane dye FM4-64 and visualized its fate using fluorescence microscopy. Since FM4-64 initially binds to the plasma membrane, followed by active endocytosis, the sub-cellular structures stained with FM4-64 in the sur7 $\Delta$ mutant (Fig. $6 \mathrm{~B})$ appear to correspond to the aberrant structures accumulating in filaments seen on electron microscopy (Fig. $5 B)$.

In order to further define the origin of these aberrant structures, we stained these cells in the yeast form with the vacuolar luminal dye carboxy-DCFDA (CDCFDA) (Fig. 7A). CDCFDA reaches the vacuole via passive diffusion in contrast to FM4-64 which is internalized through the endocytic pathway. CDCFDA and FM4-64 stained the vacuolar lumen and membrane, respectively, in control strains, DAY185 and the SUR7 complemented strain. In contrast, most of the FM4-64 dye did not reach the vacuolar membrane of the sur $7 \Delta$ null mutant, but instead remained in non-vacuolar structures as evidenced by the lack of co-staining with CDCFDA (Fig. 7A). The vacuole of the sur $7 \Delta$ null mutant is intact as shown by CDCFDA staining, and by thin section electron microscopy (Fig. 7B). Taken together these results clearly demonstrate that the structures stained by FM4-64 are not fragmented vacuoles, and are plasma membrane-derived. 


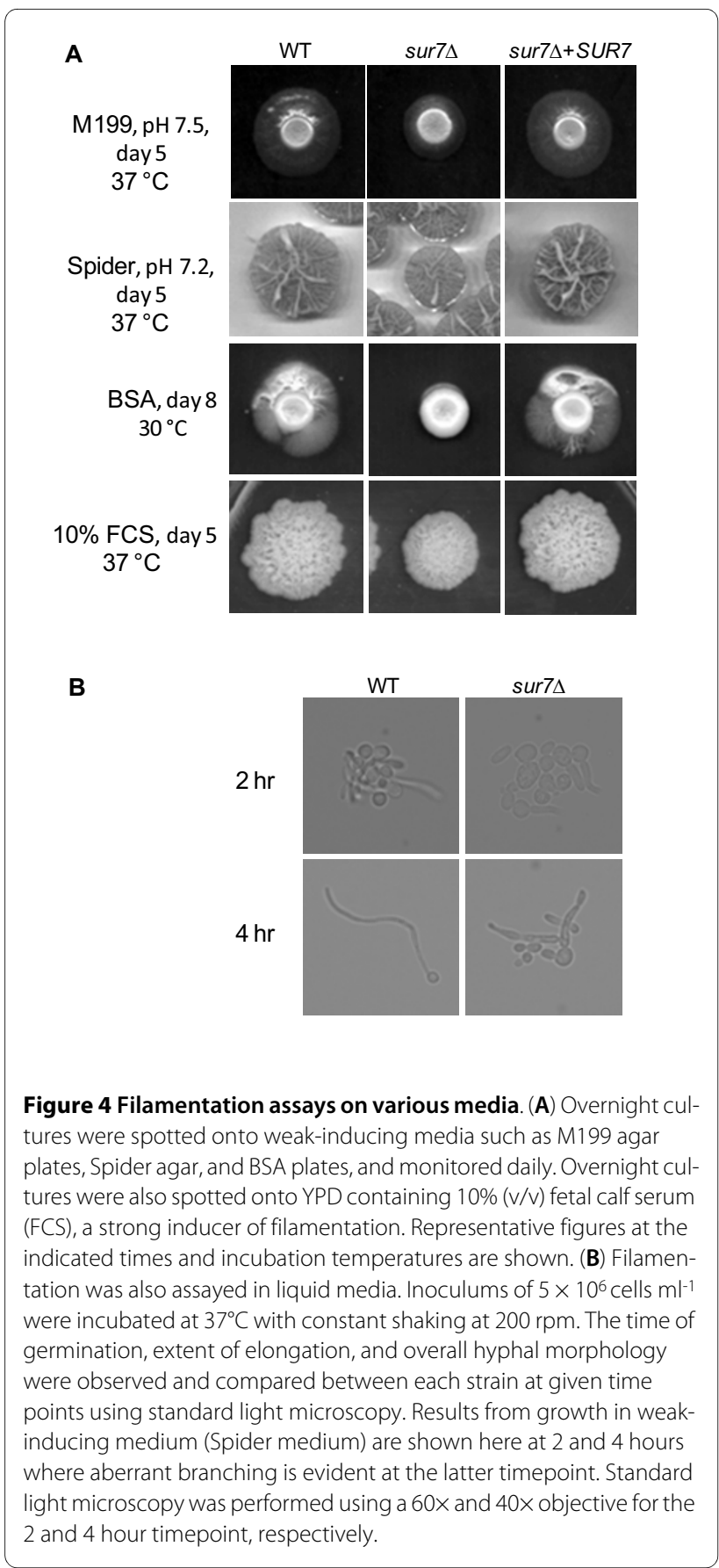

Thus, from a structural perspective, the overall plasma membrane architecture of both yeast and hyphal cells, the $C$. albicans sur7 7 null mutant is markedly abnormal.

\section{The Candida albicans sur7 $\Delta$ mutant is impaired in lipase secretion but overproduces Sap2p}

Secretion of degradative enzymes is important to pathogenesis, thus we characterized secretion of aspartyl proteases (Saps), lipase, and phospholipases in the sur $7 \Delta$ null mutant strain. When inoculated on medium containing

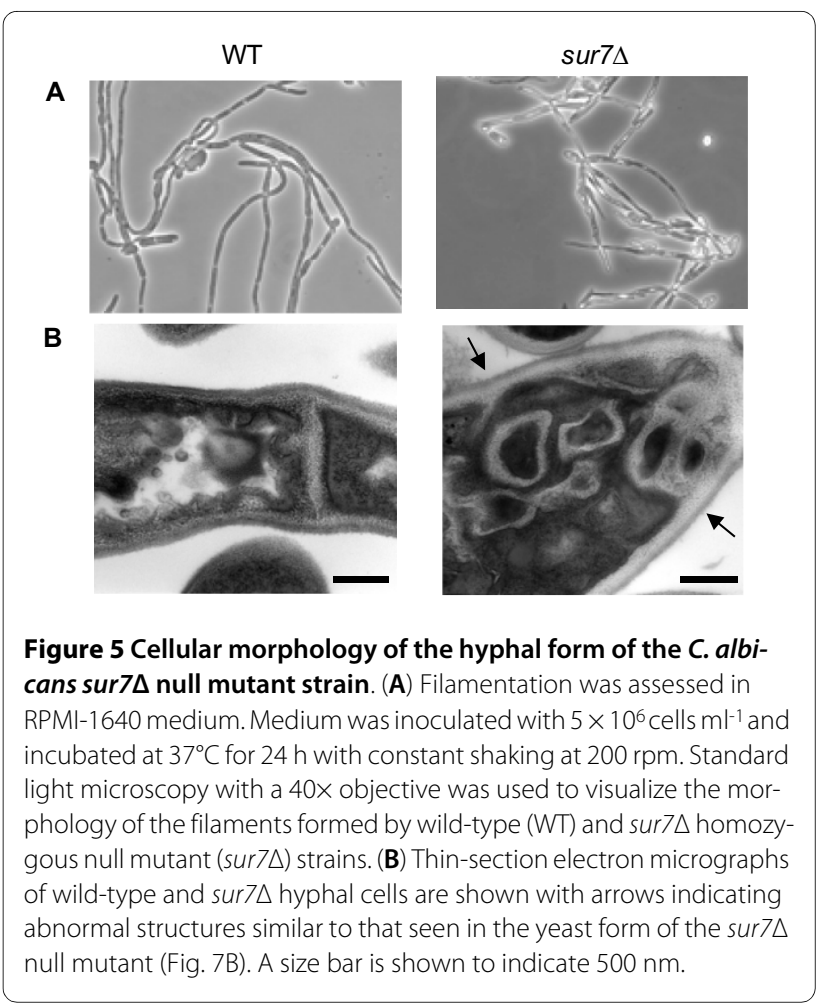

BSA as the sole nitrogen source, wild-type C. albicans secretes aspartyl proteinases which result in a halo surrounding the colony due to extracellular proteolysis. Compared to prototrophic control strain DAY185 and the isogenic complemented strain, the C. albicans sur7 $\Delta$ null mutant secreted increased extracellular proteolytic activity on BSA plates (Fig. 8A) and in liquid BSA (Fig. 8B). We next examined extracellular Sap2p secretion using Western blotting of culture supernatants using anti-Sap2p antibodies (from M. Monod). The C. albicans sur $7 \Delta$ mutant produced substantially greater amounts of extracellular Sap2p, compared to DAY185 and the complemented strain (Fig. 8C). Thus, the proteolytic degradation of BSA (Fig. 8A and 8B) is likely due to increased secretion of Sap2p. In contrast, the C. albicans sur7D mutant secreted slightly reduced amounts of extracellular Sap4-6p compared to the control and complemented strain when analyzed by Western blotting (data not shown).

We next assayed secreted phospholipase and lipase activity on egg-yolk agar and YNB-Tween 80 plates, respectively. Both phospholipase and lipase are active on egg-yolk agar plates whereas YNB-Tween 80 plates are more specific for lipase activity [28]. The sur7 $\Delta$ null mutant strain produced almost undetectable amounts of precipitation on YNB-Tween plates but only slightly less degradative activity on egg-yolk agar plates compared with control strain DAY185 and the SUR7 complemented strain (Fig. 9), thus suggesting impaired lipase secretion. 
A
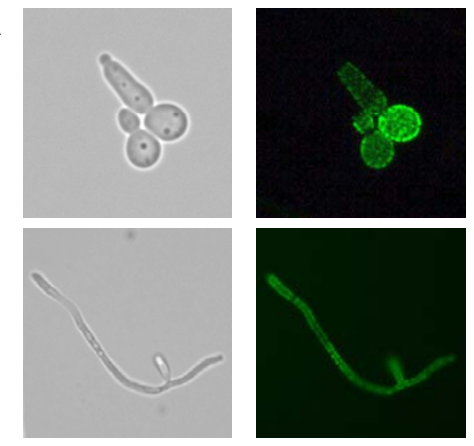

WT

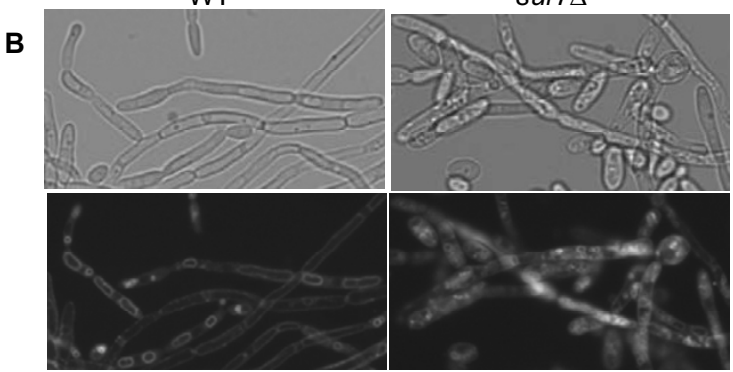

Figure 6 The role of SUR7 in endocytosis in C. albicans hyphal form. (A) Fluorescence microscopy was used to assess cellular localization of C. albicans Sur7p in the filamentous form of the SUR7-GFP strain. Hyphal growth was induced in RPMI- 1640 medium at $37^{\circ} \mathrm{C}$ and protein localization was visualized at stages of early germination (top panel) and mature hyphae formation (bottom panel). Brightfield, green fluorescent, and merged images are shown. Sur7p-GFP is observed at the plasma membrane of the germinating tube, as is the case in yeast cells, but is absent from the growing hyphal tip. (B) FM4-64 was used to stain the vacuoles in C. albicans hyphae following standard protocols for vacuolar staining of the yeast cells [41].

\section{Absence of C. albicans SUR7 increases adherence}

Adhesion plays a critical role in the early stages of C. albicans infection, and several secreted and cell wall-associated proteins contribute to this mechanism of pathogenesis (reviewed in [29] and [30]). Thus, given the observed secretory and cell wall defects of the $\operatorname{sur} 7 \Delta$ strain, we next compared the degree of adhesion between the sur7 $\Delta$ null mutant and control strains using a standard assay for adherence to polystyrene. Adherence was assayed in both RPMI-1640 (filamentation-inducing conditions) and PBS (non-inducing conditions). An increase in adherence was observed in the sur7 $\Delta$ null mutant strain compared to $S U R 7^{+}$strains (Table $3, \mathrm{p}<0.0001$ ) in either RPMI-1640 or PBS.

\section{The $C$. albicans sur7 $\Delta$ mutant forms an aberrant biofilm}

We next examined the role of C. albicans SUR7 in biofilm formation, a key contributor to Candida pathogenesis. The $C$. albicans sur7 7 mutant formed a sparse biofilm, with a patchy distribution when examined by light

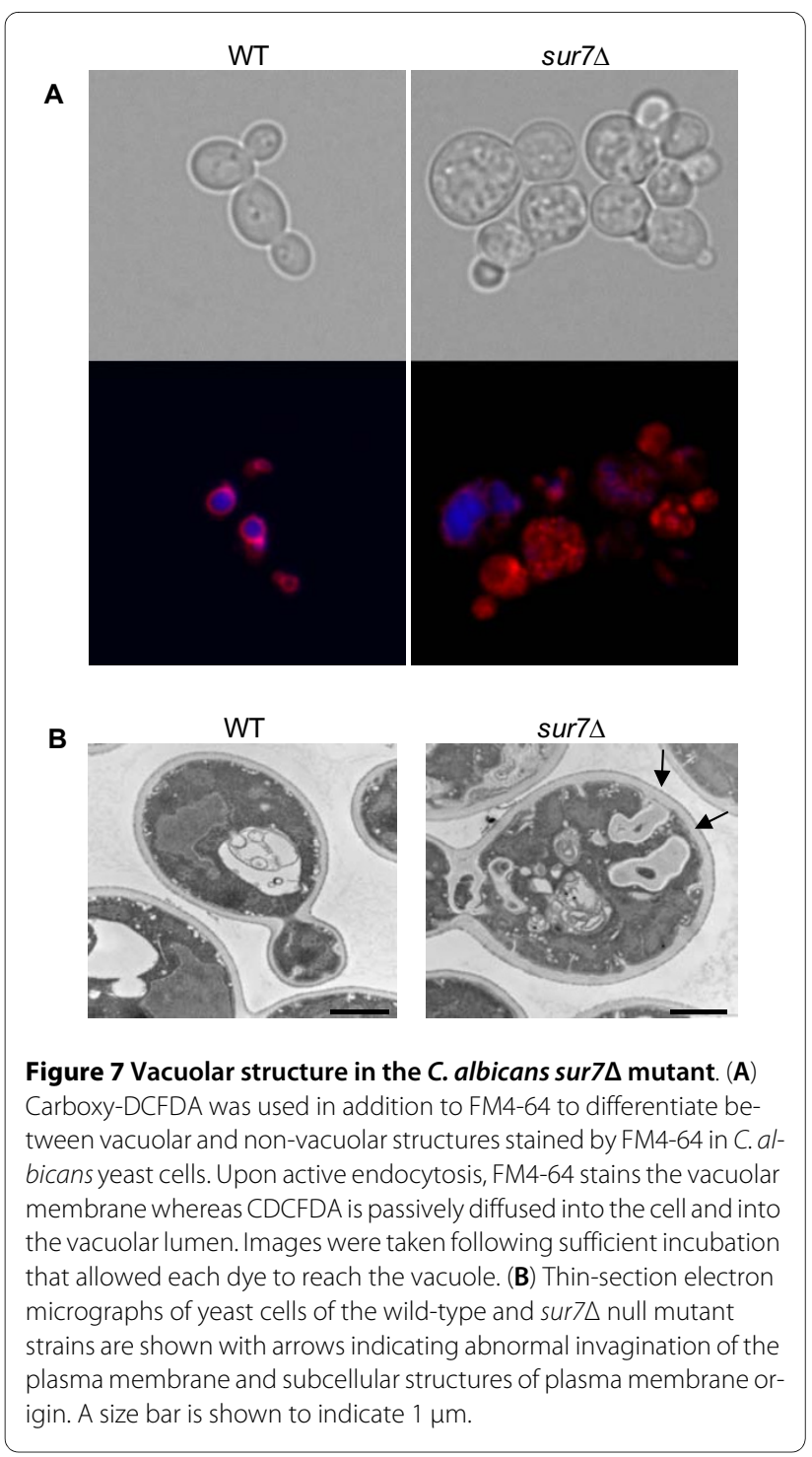

microscopy (data not shown). Because the C. albicans sur $7 \Delta$ mutant in planktonic culture generated increased XTT activity compared to controls (data not shown), we used an alternative method to measure biofilm mass. Analysis of biofilm mass using crystal violet staining showed a decrease in biofilm mass consistent with direct microscopic observation of the biofilm formed (Fig. 10A). Average $\mathrm{OD}_{630 \mathrm{~nm}}$ measurements of the crystal violet extracts, which are directly related to biofilm mass, were $0.204 \pm 0.003,0.137 \pm 0.006$, and $0.194 \pm 0.003$ for the wild-type, sur7 7 null mutant, and SUR7 complemented strains, respectively $(\mathrm{p}<0.0001)$. Examination of the biofilm by scanning electron microscopy demonstrated a sparse biofilm architecture compared to control strain DAY185 (Fig. 10B).

Next, in order to determine if the reduced biofilm mass of the sur $7 \Delta$ mutant is related to decreased attachment of the biofilm, we quantified the amount of planktonic cells 


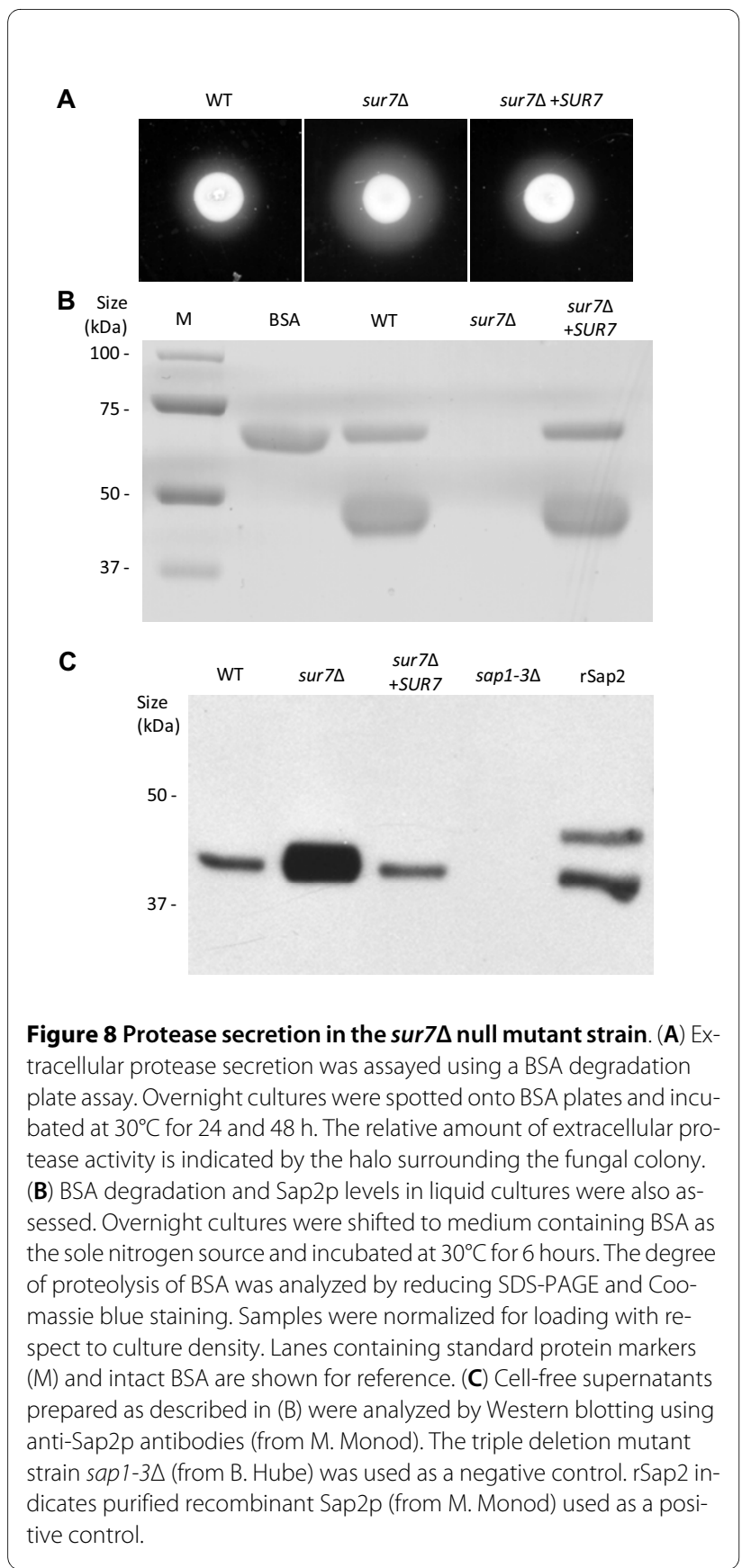

in the biofilm wash of each strain. Compared to the control strains, there were significantly fewer planktonic cells (colony forming units) present in the biofilm formed by the sur7 $\Delta$ null mutant $(\mathrm{p}<0.0001$; data not shown). These results are therefore consistent with the previous adhesion studies. Thus, reduced attachment of cells does not account for the lesser biofilm mass of the sur $7 \Delta$ null mutant. Furthermore, as there is only a minor delay or impairment in filamentation in this growth medium, it appears that the defect in biofilm formation is most likely due to a defect in cell wall or plasma membrane structure related to the absence of SUR7.

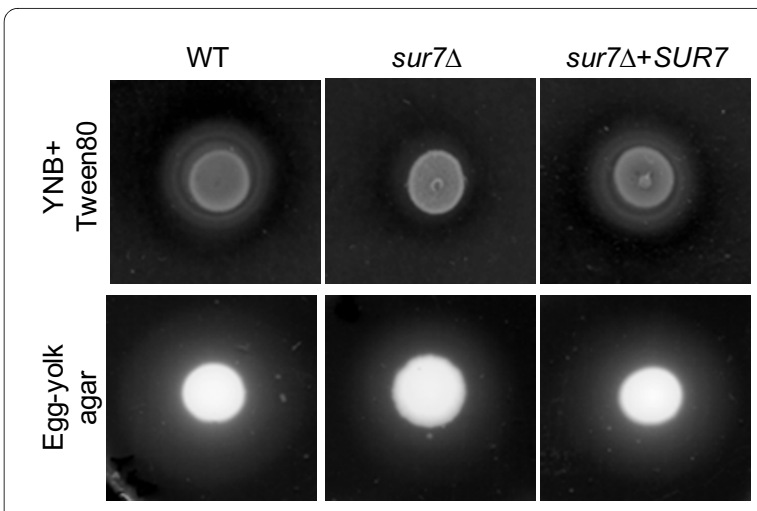

Figure 9 Extracellular lipolytic activity of the C. albicans sur7 $\mathbf{}$ null mutant. Overnight cultures were spotted onto YNB-Tween 80 and Egg-yolk agar plates and incubated at $37^{\circ} \mathrm{C}$. The relative amount of lipolytic and phospholytic degradation is indicated by the halo of precipitation surrounding the fungal colony. Phospholipases and lipases are active on Egg-yolk agar medium whereas only lipases are active on YNB-Tween 80 agar medium [28].

The $C$. albicans sur7 $\Delta$ mutant is defective in macrophage killing

Lastly, we sought to determine the effect of the loss-offunction of SUR7 on the ability of C. albicans to kill macrophage cells. At early time points ( 1 and 5 hours coincubation), the number of live macrophage cells coincubated with the sur $7 \Delta$ null mutant was similar to the numbers found when co-incubated with either DAY185 or the SUR7 complemented strain $(>1,000$ macrophages per field; data not shown). After 24 hours of co-incubation, significantly more macrophages per field remained when co-incubated with the sur $7 \Delta$ null mutant $(841 \pm 87)$ than either of the control strains ( $5 \pm 2$ and $3 \pm 1$ for wildtype and SUR7 complemented strains, respectively) (Fig. $11 \mathrm{~A}$ and $11 \mathrm{~B} \mathrm{p}<0.0001$ ). These results indicate that $C$. albicans SUR7 is required for in vitro macrophage killing.

\section{Discussion}

Using a bioinformatics approach, we previously identified predicted secretion pathway proteins in Candida albicans [14] and next compared this with published transcriptional profiling data to identify genes highly expressed during conditions similar to bloodstream infection [15]. This approach identified a number of genes known to be involved in pathogenesis, among them SUN41 and SOD5, which have recently been studied in detail [17-21]. Among several other unknown open reading frames, we identified the C. albicans homolog of $S$. cerevisiae SUR7, which has recently been described in $C$. albicans as required for proper plasma membrane organization and cell wall synthesis [2]. Thus, we sought to investigate the role of $C$. albicans SUR7 in virulencerelated phenotypes, including filamentation, aspartyl pro- 
Table 3: Adhesion of C. albicans strains to polystyrene.

Relative adherence units

\begin{tabular}{|c|c|c|c|}
\hline & WT & sur7 * & sur7 +SUR7 \\
\hline PBS & $0.798 \pm 0.024$ & $1.310 \pm 0.035$ & $0.801 \pm 0.012$ \\
\hline RPMI-1640 & $0.621 \pm 0.006$ & $0.776 \pm 0.007$ & 0.6430 .019 \\
\hline
\end{tabular}

${ }^{*} p$-value $<0.0001$

tease (Sap) and lipase secretion, biofilm formation, and virulence using an in vitro macrophage killing model.

We first assessed the structural role of C. albicans SUR7 from a general cellular and physiologic perspective. Lossof-function of SUR7 resulted in the formation of aberrant plasma membrane invaginations and accumulation of subcellular structures inside the $C$. albicans cells, whether in the hyphal or the yeast form. Similar invaginations were observed in a $S$. cerevisiae pil1 $\Delta$ deletion mutant [3], and S. cerevisiae Pillp has been shown to be involved in the localization of S. cerevisiae Sur7p to the plasma membrane. In addition, the $C$. albicans sur7 $\Delta$ mutant was hyper-susceptible to sub-inhibitory concentrations of caspofungin but not to either amphotericin $B$

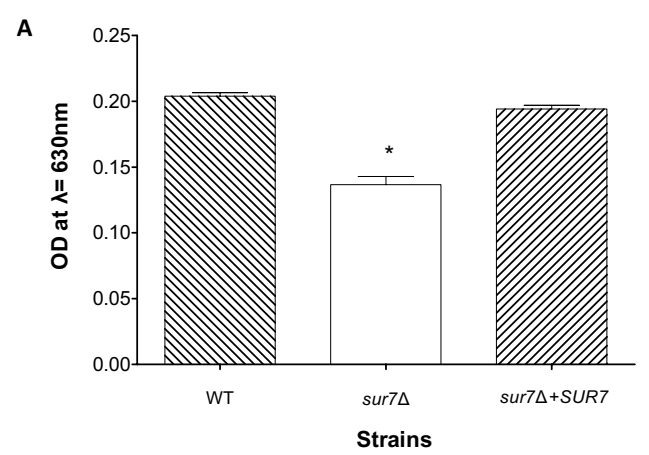

B

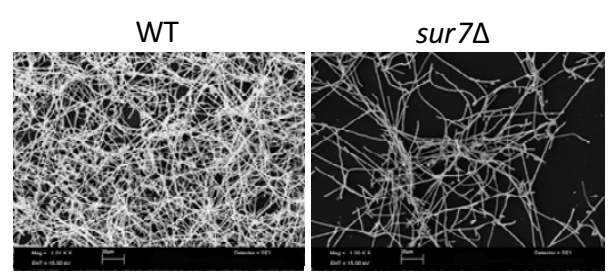

Figure 10 Analysis of C. albicans sur7 $\Delta$ biofilm formation. (A) Biofilm mass was assayed by staining the biofilm formed with Crystal Violet [45]. Data analyzed consisted of 14 replicates and statistical significance was determined by ANOVA ( $p$-value $<0.0001$ ), indicated on the figure with an asterisk $(*)$. (B) The structure and morphology of the biofilm formed by the sur $7 \triangle$ null mutant strain and wild-type strain DAY185 was examined by scanning electron microscopy. Size bars indicate $20 \mu \mathrm{m}$. or 5-fluorocytosine. Caspofungin inhibits $\beta$-1,3-glucan synthase thus altering cell wall composition leading to cell lysis of Candida cells [31]. Moreover, we have demonstrated that growth of the sur $7 \Delta$ null mutant was sensitive to SDS, Congo Red, and Calcofluor White. These results suggest that SUR7 plays a role in maintenance of cell wall integrity of both the yeast and filamentous form of C. albicans.

There was no impairment in the ability of the sur $7 \Delta$ null mutant strain to tolerate general osmotic stresses or growth at $37^{\circ} \mathrm{C}$. Likewise, in S. cerevisiae, the growth of the sur $7 \Delta$ mutant, and null mutants of the SUR7 paralogs

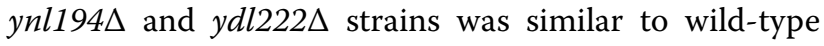
under conditions of high salt or elevated temperatures [4]. However, growth of the $C$. albicans sur $7 \Delta$ mutant was markedly impaired at $42^{\circ} \mathrm{C}$, a phenotype that was partially rescued by the addition of $1.0 \mathrm{M} \mathrm{NaCl}$. We demonstrated that the fluorescently-tagged C. albicans Sur7p paralog Fmp45p co-localizes with Sur7p-GFP. We further demonstrated increased fluorescence intensity of the $C$. albicans Sur7p paralog Fmp45p, in the presence of high salt $(1.0 \mathrm{M} \mathrm{NaCl})$ in both the SUR7 ${ }^{+}$and SUR7- strains. Thus the cellular localization and increased fluorescence intensities suggest that Fmp45p may play a role in survival at high temperature and salt conditions in the $\operatorname{sur} 7 \Delta$ mutant. This suggests functional similarities between SUR7 and FMP45 that are important for growth and survival in more extreme environmental conditions. We have so far been unsuccessful in our efforts to generate a C. albicans sur $7 \Delta$ fmp $45 \Delta$ null mutant, and it remains to be determined if these genes are synthetic lethal in $C$. albicans.

There is limited data on the role of endocytosis in Candida pathogenesis. Previously, C. albicans ORFs homologous to $S$. cerevisiae endocytosis genes were investigated for their involvement in polarized cell growth [32]. Specifically, the authors examined $A B P 1, B Z Z 1, E D E 1$, and $P A N 1$, whose gene products are involved in the early stages of endocytosis [33]. Loss of function of PAN1, but not $A B P 1, B Z Z 1$, or $E D E 1$, resulted in altered hyphal formation [32]. More recently, Douglas et al [34] investigated the role of C. albicans RVS161 and RVS167 whose 


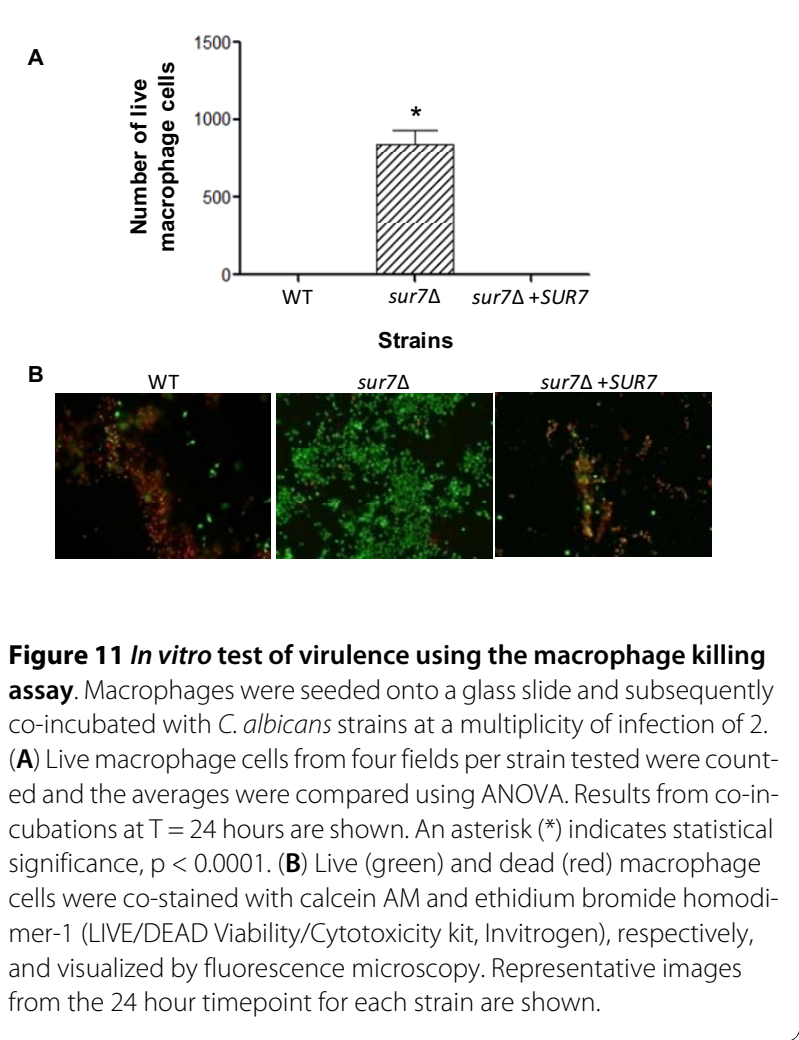

homologues in S. cerevisiae are involved in the severance of budding endocytic vesicles from the plasma membrane. Deletion of these genes resulted in strains that produced aberrant filamentous structures and exhibited decreased virulence in a mouse model of disseminated candidiasis [34]. In S. cerevisiae, SUR7 localizes to eisosomes which are immobile protein assemblies that mark sites on the plasma membrane for endocytosis [3]. Defective endocytosis as a result of the deletion of SUR7 in C. albicans has been described for the yeast form of this important pathogen [2]. However, the role of C. albicans SUR7 in pathogenesis has not been previously examined. We present here results of experiments whose main focus was to characterize the structural and physiologic role of C. albicans SUR7, in order to provide a foundation to understanding the role of SUR7 in pathogenesis.

Thus, we next turned our attention to assessing the functional contribution of C. albicans SUR7 to several key virulence-related attributes. The $C$. albicans sur $7 \Delta$ mutant was delayed in filamentation when induced on solid media, although this overall defect was minor. Microscopic examination revealed that the sur $7 \Delta$ filaments branched extensively, and ultrastructurally contained subcellular structures resembling those seen in the C. albicans sur7 $\Delta$ yeast cells. Alvarez et al. [2] also describe pseudohyphal growth of the sur $7 \Delta$ mutant strain including an apparent defect in cell polarization, as evi- denced by weak filipin staining. However, it is not clear why C. albicans SUR7 affects Sap or lipase secretion, as there is currently little known of the role of endocytosis in the secretion of Saps, lipases, and phospholipases.

Importantly, the $C$. albicans sur $7 \Delta$ mutant formed a patchy biofilm, with many areas of scant cells and filaments. As we demonstrated an increase in adhesion in the $\operatorname{sur} 7 \Delta$ mutant, and only a minor delay in filamentation, this markedly defective biofilm cannot be attributed to reduced adhesion or defective filamentation. Instead, we postulate that the marked plasma membrane and cell wall defects that we demonstrated in the structural studies of the $\operatorname{sur} 7 \Delta$ mutant may be responsible for this defective biofilm. Biofilm formation is a complex, still incompletely understood process. However, cell-cell communication and adhesion are an important part of biofilm formation. We suspect that the marked derangement in plasma membrane and cell wall organization may affect the ability of the $C$. albicans sur $7 \Delta$ mutant to form a normal biofilm.

Alternatively, it is possible that SUR7 is involved in biofilm detachment, as a negative regulator. Recently, Sellam et al. [35], performed transcriptional profiling to identify genes potentially involved in biofilm detachment (where cells from a mature biofilm detach in order to spread to distant sites within the bloodstream of an infected host). In their experiments, levels of SUR7 transcript were down-regulated during the initial steps of biofilm detachment. During biofilm detachment, the biofilm was observed to detach from the surface in patches. This is in agreement with the patchy morphology of the biofilm formed by the sur7 $\Delta$ homozygous null mutant strain. Thus, we present another hypothesis that $S U R 7$ may be a negative regulator of biofilm detachment, and we are currently investigating the role of SUR7 in biofilm detachment.

We next assayed virulence in a macrophage killing assay in vitro. We clearly demonstrated that the sur $7 \Delta$ mutant strain was greatly reduced in its ability to kill murine macrophage cells at 24 hours, which is similar to the virulence defect seen in a C. albicans vps $11 \Delta$ mutant [36]. Again, we suspect that the marked abnormalities in plasma membrane and cell wall structure render the $C$. albicans sur $7 \Delta$ mutant more susceptible to macrophage killing.

\section{Conclusions}

C. albicans SUR7 shares some functional homology to $S$. cerevisiae SUR7, but unlike in S. cerevisiae, C. albicans $S U R 7$ may play a role in endocytosis and the maintenance of cell wall integrity. C. albicans SUR7 contributes to several key virulence-related phenotypes, and thus, may have additional molecular functions in this highly adapt- 
able, pathogenic organism. Of note, SUR7 appears to be fungal-specific, with no clear human homologue. Given the phenotypes we describe here and its increased expression during infection [15], we are further investigating whether C. albicans SUR7 plays a role in biofilm detachment and the dissemination of infection.

\section{Methods}

\section{Strains and media}

C. albicans strains used in this study are indicated in Table 1 . Strains were routinely grown at 30 (C in YPD (1\% yeast extract, $2 \%$ peptone, $2 \%$ glucose) supplemented with uridine $\left(80 \mu \mathrm{g} \mathrm{ml}^{-1}\right)$, or in complete synthetic medium $(0.67 \%$ yeast nitrogen base without amino acids [YNB], 2\% glucose, $0.079 \%$ Complete Synthetic Mixture). Filamentation was assayed at $37^{\circ} \mathrm{C}$ in the following media with agar: Medium 199 containing Earle's salts (Invitrogen) supplemented with L-glutamine and buffered with $150 \mathrm{mM}$ HEPES to $\mathrm{pH}$ 7.5; RPMI-1640 supplemented with L-glutamine (US Biological) and buffered with 165 mM MOPS to $\mathrm{pH} 7.0$ (referred to as "RPMI-1640" from this point onward); $10 \%(\mathrm{v} / \mathrm{v})$ fetal calf serum in YPD; and Spider medium as described by Liu et al [37]. Liquid hyphal-inducing media were inoculated with cells from overnight cultures to achieve a starting density of $5 \times 10^{6}$ cells $\mathrm{ml}^{-1}$, followed by incubation with shaking at $200 \mathrm{rpm}$ at indicated time points, and visualization by microscopy. Solid media were prepared by adding $2 \%(\mathrm{w} / \mathrm{v})$ agar.

\section{Preparation of plasmid and genomic DNA}

Plasmids were expanded in Escherichia coli DH5 $\alpha$ competent cells (Invitrogen) grown in LB medium with ampicillin $\left(100 \mu \mathrm{g} \mathrm{ml}^{-1}\right)$ at $37^{\circ} \mathrm{C}$. Plasmid DNA was prepared from E. coli strains using the Fast Plasmid Mini Kit ${ }^{\mathrm{m}}$ (5PRIME) following the manufacturer's instructions. Genomic DNA was extracted from yeast cells using the Masterpure $^{\mathrm{Tn}}$ Yeast DNA Purification Kit (Epicentre Biotechnologies) according to manufacturer's instructions with the exception of an extended incubation step $(1 \mathrm{hr}$ on ice) performed after the addition of the MPC Protein Precipitation Reagent.

\section{Analysis and targeted disruption of C. albicans SUR7}

The putative C. albicans SUR7 open reading frame (orf19.3414) was identified in a genome-wide search for proteins that compose predicted C. albicans secretion pathway proteins [14]. The most current annotation of this gene was verified at the Candida Genome Database http://www.candidagenome.org and CandidaDB http:// genodb.pasteur.fr/cgi-bin/WebObjects/CandidaDB.

The $C$. albicans sur7 $\triangle$ null mutant, in background strain BWP17, was generated by disrupting both chromosomal alleles of C. albicans SUR7 using a PCR-based gene disruption strategy [22,23]. PCR-generated amplicons were generated using the synthetic oligonucleotides shown in Table 4 and plasmid pDDB57 (from A.P. Mitchell, Carnegie Mellon Univ.) as the template. C. albicans BWP17 was transformed directly with the PCR reaction mixtures using the lithium acetate method. Uridine prototrophs were selected and purified on synthetic media lacking uracil and uridine, genomic DNA was extracted using the Masterpure ${ }^{\mathrm{Tm}}$ Yeast DNA Kit (Epicentre), and homologous integration of the gene targeting cassette was verified by allele-specific PCR, using one primer upstream and one primer downstream of the open reading frame and outside of the targeting region of the disruption cassette (Table 4).

To disrupt the second SUR7 allele, selected C. albicans SUR7/sur7A::dpl200-URA3-dpl200 mutants were transformed with the PCR-generated gene disruption cassette, similar to the process of creating the first allele knockout strains, except plasmid pRS-Arg4 $\Delta$ SpeI [22] was used as the template. Histidine prototrophy was restored after transforming the resulting strain with NruI-linearized pGEM-HIS1 [22].

In order to generate an isogenic SUR7 complemented strain, a copy of wild-type SUR7 was sub-cloned into pGEM-HIS1, digested with NruI, and transformed into the sur $7 \Delta:: U R A 3 /$ sur $7 \Delta:: A R G 4$ strain. Reverse and forward sequencing of the cloned SUR7 gene was performed, and confirmed that the sequence was identical to the CGD Assembly 21 SUR7 sequence. Correct integration of the wild-type gene was confirmed by allele-specific PCR in multiple independent transformants. Standard methods were used for restriction mapping, subcloning, DNA sequencing, and lithium acetate transformation [38].

Strain construction was verified by Southern blotting and standard blotting and hybridization techniques [38]. Briefly, genomic DNA digested with Hind III and Cla I, was run on a $0.8 \%(\mathrm{w} / \mathrm{v})$ agarose gel. DNA fragments were subsequently transferred by capillary action to a positively charged nylon membrane (Roche Applied Science) using 20× Saline Sodium Citrate buffer. A 1.1 kb DIGlabelled PCR amplicon from C. albicans SUR7 (n.t. -585 to +541 of orf19.3414) was then used to probe the membrane. Detection of Hind III/Cla I DNA fragments of the expected band sizes for the wild-type allele (SUR7; 3.6

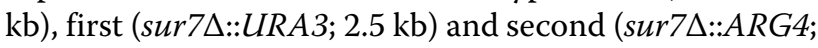
$1.4 \mathrm{~kb}$ ) allele knockout cassettes confirmed the genotype of each strain used in this study (Additional File 1).

\section{Construction and analysis of FMP45-GFP tagged C. albicans strains}

Green-fluorescent protein-tagged (GFP) strains of $C$. albicans FMP45 (orf19.6489) were generated using PCRmediated insertion of GFP according to published methods, using primers FMP45-5FP and FMP45-3HisR2 and 
Table 4: Primer sequences used in this study.

\begin{tabular}{|c|c|}
\hline Primer & Primer sequence (5' T 3') \\
\hline IPF12442-5DR & $\begin{array}{l}\text { TTATTCTTTGAATTACTTTCCAACTT } \\
\text { ACTTCATTCCCAATTGATTAAAGTTA } \\
\text { TAAAGAATTAAACGAAACGTTTTCCC } \\
\text { AGTCACGACGTT }\end{array}$ \\
\hline IPF12442-3DR & $\begin{array}{l}\text { TACGATTTCTTAATCAAATATCAAAC } \\
\text { TTTAACCСTCTCAAAAAGCTAATAAA } \\
\text { CTAACATTGATTACTCAATGTGGAAT } \\
\text { TGTGAGCGGATA }\end{array}$ \\
\hline IPF12442-5Det & GСTATTCCACTTCCAСTTGG \\
\hline IPF12442-3Det & CAAGGGGGGAGAAGAATGGG \\
\hline Sall-5'-IPF12442 & $\begin{array}{l}\text { GTTCTGTCGACTTGGTTGGTTGGTTG } \\
\text { GTT }\end{array}$ \\
\hline Ndel-3'IPF12442 & САATCCATATGTAACTCATGTCACGC \\
\hline FMP45-5FP & $\begin{array}{l}\text { GGCGAAAGACTCTCTAATGCATCAAA } \\
\text { ATTCAGATTTTTTAGAGTGAAAAGAG } \\
\text { CCAAATCAGAAGATGTTGGTGGTGGT } \\
\text { TCTAAAGGTGAAGAATTATT }\end{array}$ \\
\hline FMP45-3HisR2 & $\begin{array}{l}\text { AAATTCATAATGGGTGTAGTTTAAGC } \\
\text { CCAAAAAATTCAACAGTACAATCAAT } \\
\text { GAGGACTTTTTCTTCATTGAATTCCG } \\
\text { GAATATTTATGAGAAAC }\end{array}$ \\
\hline FMP45FP-5Det & СССTCGTGGTGAATACGAATC \\
\hline SUR7-5FP & $\begin{array}{l}\text { GAAGAAAACACAGGCGGTATTAGATT } \\
\text { CTTCAAAATCAAAAGAAACCAAAAAG } \\
\text { TTTCCGATGATGAATCAGTAGGTGGT } \\
\text { GGTTCTAAAGGTGAAGAATTATT }\end{array}$ \\
\hline SUR7-3HisR2 & $\begin{array}{l}\text { TACGATTTCTTAATCAAATATCAAAC } \\
\text { TTTAACCCTCTCAAAAAGCTAATAAA } \\
\text { CTAACATTGATTACTCAAGAATTCCG } \\
\text { GAATATTTATGAGAAAC }\end{array}$ \\
\hline SUR7FP-5Det & СTAGAGCTGCCCCACCAACT \\
\hline FMP45-3UraR1 & $\begin{array}{l}\text { AAATTCATAATGGGTGTAGTTTAAGC } \\
\text { CCAAAAAATTCAACAGTACAATCAAT } \\
\text { GAGGACTTTTTCTTCATTTCTAGAAG } \\
\text { GACCACCTTTGATTG }\end{array}$ \\
\hline ADHTERAS [39] & GAGATATCGATCCTAGCGTAG \\
\hline 3FP-URADet & GTGACACCATGAGCATTGGT \\
\hline
\end{tabular}

plasmid pMG1646 (pGFP-HIS1) as a template [39]. This method allows for genomic integration of GFP-coding sequences at the $\mathrm{C}$-terminus of the protein of interest while maintaining control of expression of the fusion protein under its native promoter. Transformants were selected on medium lacking histidine, and confirmation of correct integration into strains BWP17 (SUR7/SUR7) and SMB3 (sur $7 \Delta /$ sur $7 \Delta$ ) was performed by allele-specific PCR on genomic DNA extracted from independent transformants. Localization of Fmp45p-GFP was performed using laser scanning confocal microscopy of live cells grown in complete synthetic medium in the presence or absence of $1.0 \mathrm{M} \mathrm{NaCl}$ at $42^{\circ} \mathrm{C}$. Images were acquired on the Zeiss LSM700 on an Axio Observer Z1 (Carl Zeiss MicroImaging Inc). Image $\mathrm{J}$ software (National Institutes of Health; http://rsb.info.nih.gov/ij) was used to quantify fluorescence intensity of representative cells using the Plot Profile function. Median fluorescence intensity indicates the overall fluorescence intensity of a representative cell.

Additionally, a double fluorescent tagged strain was constructed to study the cellular localization of Fmp45p with respect to Sur7p localization. First we created a SUR7-YFP strain as described in the previous paragraph except that the PCR amplicon used was generated using pMG1656 (pYFP-HIS) [39] and primers SUR7-5FP and SUR7-3HisR2 (Table 4). The resulting strain was next transformed with PCR amplicons generated using primers FMP45-5FP and FMP45-3UraR1 and pMG1602 (pGFP-URA) [39] and transformants were selected on medium lacking uracil and uridine. An additional control strain, SUR7-GFP, was also created using pMG1646 (pGFP-HIS) as a template [39] and primers SUR7-5FP and SUR7-3HisR2. Correct integration of the SUR7-YFP, SUR7-GFP, and FMP45-GFP alleles were verified by allele-specific PCR on genomic DNA extracted from independent transformants, using primer pairs SUR7FP5Det and ADHTERAS; and FMP45FP-5Det and 3FPURADet, respectively. Images were acquired on a Zeiss Axioskop 2MOT microscope using the Nuance ${ }^{\mathrm{Tm}}$ Multispectral Imaging System (CRi). Using the microscope's green fluorescence filter set (Ex: 475/28 nm; Em: $515 \mathrm{~nm}$ LP; Single-band dichroic: $519 \mathrm{~nm}$ ), a series of images (spectral cube) was acquired at $10 \mathrm{~nm}$ intervals from 500 $-720 \mathrm{~nm}$ as defined by the Nuance ${ }^{\mathrm{Tm}}$ system's liquid crystal tunable filter. Spectral cube images were acquired from control strains: auto-fluorescence (DAY185), YFP only (SUR7-YFP), and GFP only (SUR7-GFP), as well as from the SUR7-YFP FMP45-GFP multiply-expressing strain. Using Nuance software, pure spectra were generated for autofluorescence, GFP and YFP which were subsequently used to unmix spectral cubes acquired of the SUR7-YFP FMP45-GFP strain. Following linear unmixing, the individual fluorophore-tagged proteins were 
viewed in separate component images, with the extent of GFP-YFP co-localization indicated in a merged image. Although there is significant overlap of the fluorescence emission spectra of GFP and YFP that cannot be distinguished using conventional epifluorescence imaging, acquisition and unmixing of spectral images using the Nuance $^{\text {Tw }}$ spectral imaging camera allowed these spectrally distinct fluorophores to be individually detected. Details of strains and primers used in this study are found in Tables 1 and 4.

\section{Analysis of growth and stress tolerance}

Growth was assessed in liquid media by measuring $\mathrm{OD}_{600}$ at fixed intervals in an automated Bioscreen $\mathrm{C}$ Analyzer (Thermo Labsystems) as described previously [40]. Growth curves were generated using Prism 5.0 (GraphPad Software, Inc). Strains were analyzed in conditions of high osmolar stress $(2.5 \mathrm{M}$ glycerol or $1.0 \mathrm{M} \mathrm{NaCl})$ and varying temperatures $\left(30,37\right.$, or $\left.42^{\circ} \mathrm{C}\right)$. Strains grown in complete synthetic medium supplemented with uridine were also exposed to sub-inhibitory concentrations of caspofungin, amphotericin B, and 5-fluorocytosine. Pilot growth curves were first generated to determine the working concentration of each antifungal reagent to be used. The final concentrations of caspofungin, amphotericin $\mathrm{B}$, and 5-fluorocytosine used for phenotypic analysis were $0.25,0.5$, and $10 \mu \mathrm{g} \mathrm{ml}^{-1}$, respectively. Cell wall integrity was tested on YPD agar medium containing Calcofluor White (20,50, and $\left.125 \mathrm{\mu g} \mathrm{ml}^{-1}\right)$, caspofungin (0.1, 0.2 , and $0.5 \mu \mathrm{g} \mathrm{ml}^{-1}$ ), Congo Red (50, 100, and $200 \mu \mathrm{g} \mathrm{ml}^{-}$ $\left.{ }^{1}\right)$, or SDS (0.01\%, $0.02 \%$, and $\left.0.05 \%\right)$.

\section{Endocytosis assay and visualization of vacuolar morphology}

The effect of the loss of function of SUR7 on endocytosis in both the yeast and filamentous forms was assessed by following the fate of the lypophilic dye FM4-64 [41]. For dual staining with carboxy-DCFDA (CDCFDA; Invitrogen), cells were first stained with FM4-64. Next, $1.0 \times 10^{6}$ cells $\mathrm{ml}^{-1}$ were resuspended in $50 \mathrm{mM}$ sodium citrate buffer and CDCFDA was added according to the manufacturer's instructions. Following a 15 minute incubation period at room temperature, microscopy then was performed on a Nikon Eclipse 80i fluorescent microscope (Nikon Instruments, Inc.). Images were acquired and color added using NIS-Elements Documentation software, version 2.34 (Nikon Instruments, Inc.).

\section{Enzyme assays}

Extracellular protease secretion was assayed on BSA plates [42]. Lipase activity was visualized on egg-yolk agar plates and YNB agar containing 2.5\% (v/v) Tween 80 [28]. BSA degradation in liquid media was assessed by SDSPAGE, followed by analysis of Sap2p secretion by West- ern blot analysis as described [43], except that the medium used was $1.18 \%$ Yeast Carbon Base (YCB, Difco $\left.^{\mathrm{rt}}\right), 0.01 \%$ yeast extract, and $0.1 \%$ BSA. Equivolumes of culture supernatants were loaded from each strain, using the same concentration of cells for each strain. Saps $4-6 \mathrm{p}$ were induced by growing strains, at a starting concentration of $5 \times 10^{6}$ cells ml-1 in RPMI- 1640 , at $37^{\circ} \mathrm{C}$ for $24 \mathrm{~h}$ with shaking at $200 \mathrm{rpm}$. Saps 4-6p secreted into the media were analyzed by Western blot using anti-Sap5p polyclonal antibody (from M. Monod), after transferring to PVDF membrane (Bio-Rad), and detection using chemiluminescence (ECL Plus Detection Kit, GE Healthcare Life Sciences) and autoradiography.

\section{Adhesion assays}

Adhesion to polystyrene was assessed as described previously [44] with slight modifications. An inoculum of $1.0 \times$ $10^{7}$ cells $\mathrm{ml}^{-1}$ in PBS or RPMI-1640 was prepared, of which $150 \mu \mathrm{l}$ was added to individual wells of a 96-well microtiter plate. An identical set of each strain was dispensed into individual microcentrifuge tubes for use as the unwashed control, representing the total number of adherent and non-adherent cells. Following a 2-hr incubation period at $37^{\circ} \mathrm{C}$, non-adherent cells were removed by washing the wells of the microtiter plate, while cells incubated in microcentrifuge tubes were pelleted at high speed on a benchtop centrifuge. The XTT-reduction assay [45] was then used to quantify the adhered and total amount of cells in each well and microcentrifuge tube, respectively. After incubation with the XTT-menadione substrate at $37^{\circ} \mathrm{C}$ for 3 hours, $75 \mu$ l of colored formazan was transferred to a fresh microtiter plate and absorbance was read at $490 \mathrm{~nm}$. The adherence capacity of each strain was calculated as the mean XTT-value of the washed cells relative to the mean XTT-value of the unwashed cells. Experiments were performed at least twice, each with 8 replicates per strain tested. Statistical significance was assessed with an analysis of variance (ANOVA) between all strains compared using Prism 5.0 (GraphPad Software, Inc.)

\section{Analysis of fungal biofilms}

Formation of C. albicans biofilms and the XTT-reduction assay were performed as previously described [45]. As an alternative, Crystal Violet staining was used to estimate the biofilm mass [45]. Briefly, biofilms were stained with $100 \mu \mathrm{l}$ of a $0.3 \%(\mathrm{w} / \mathrm{v})$ Crystal Violet, $5 \%(\mathrm{v} / \mathrm{v})$ isopropanol, $5 \%(\mathrm{v} / \mathrm{v})$ methanol solution for $5 \mathrm{~min}$, after which the wells were washed with water. The dye was then extracted from the biofilms using $100 \mu \mathrm{l}$ ethanol, of which $75 \mu \mathrm{l}$ was transferred to a clean microtiter plate and the absorbance was measured spectrophotometrically at 550 $\mathrm{nm}$. Scanning electron microscopy was performed on biofilm samples formed on a coverslip (Thermanox, 
Nalge Nunc International) after $24 \mathrm{~h}$ incubation of a 0.5 $\mathrm{ml}$ inoculum containing $1.0 \times 10^{6}$ cells ml-1 according to previously described methods [46]. Non-adherent, planktonic cells were quantified from biofilm washes by plating serial dilutions of the pooled washes, from individual replicates, onto YPD agar plates, and colony forming units were determined following incubation at $30^{\circ} \mathrm{C}$ for 2 days.

\section{Macrophage killing assays}

The macrophage killing assay was performed as described by Palmer et al. [36]. The murine macrophage cell line used in this study, J774A.1, was purchased from ATCC and propagated in high glucose D-MEM supplemented with $10 \%$ FCS. Next, $2.0 \times 10^{5}$ J774A.1 cells in a volume of $0.75 \mathrm{ml}$ were seeded in Lab-Tek Chambered Slides (Nalge-Nunc), incubated overnight at $37^{\circ} \mathrm{C}$ with $5 \%$ $\mathrm{CO}_{2}$. C. albicans strains, diluted and grown as previously described [47], were co-incubated with the adhered macrophage at a multiplicity of infection (MOI) of 2, for a specified period of time. Following co-incubation, the cells were washed twice with phosphate-buffered saline (PBS) and viability was assessed using $0.2 \mu \mathrm{M}$ calcein AM and $4 \mu \mathrm{M}$ ethidium bromide homodimer (LIVE/DEAD Viability/Cytotoxicity kit, Invitrogen) according to the manufacturer's instructions. Live macrophages from four fields of each chamber were counted and statistical differences between the average values was assessed using ANOVA followed by Tukey's multiple comparison of means.

\section{Additional material}

Additional file 1 Confirmation of sur $7 \Delta$ heterozygous and homozygous null mutants by Southern blot. Southern hybridization was performed on Hind III-Cla I digests of genomic DNA of transformants of interest using a DIG-labeled probe that hybridizes to n.t. -585 to +541 of C. albicans SUR7. The expected sizes of the restriction fragments are: wild-type (SUR7) allele $3.6 \mathrm{~kb}$, 1 st allele gene replacement (sur7 $\triangle:: U R A 3) 2.5 \mathrm{~kb}$, and $2^{\text {nd }}$ allele gene replacement (sur7 $\because: A R G 4) 1.4 \mathrm{~kb}$. Genomic DNA from the wild-type strain (SUR7/SUR7), DAY185, was run in the first lane marked "WT". Genomic DNA from a heterozygous null mutant (sur7 $\triangle$ SSUR7) isolate was run in the second lane marked " $\triangle /+$ ". Genomic DNA from two independent homozygous null mutant strains (sur $7 \Delta /$ sur $7 \Delta$ ) was run in the lanes marked " $\Delta / \triangle$ ". Size markers from standard Hind III digest of lambda DNA is shown on the left for reference.

\section{Authors' contributions}

SMB participated in the design and performed all experimentation presented in the manuscript, except where acknowledged in appropriate section(s). SAL conceived of the study, correlated the bioinformatics data with published in vivo and in vitro transcription profiling data, and participated in the design of the experiments. All authors contributed towards the analysis and interpretation of results towards intellectually significant findings, drafted, read, and approved the final manuscript for submission.

\section{Authors' information}

SAL is a physician-scientist (MD, Ph.D) who is the Chief of Infectious Diseases at the New Mexico VA Healthcare System, and Assistant Professor at the School of Medicine of the University of New Mexico (Albuquerque, NM).

\section{Acknowledgements}

We thank Aaron P. Mitchell (Carnegie Mellon University) for providing strain BWP17 and plasmids pDDB57, pRS-ARG4 $\triangle$ Spel, and pGEM-HIS1. We thank Maryam Gerami-Nejad and Cheryl Gale (University of Minnesota) for providing plasmids pMG1646, pMG1602, and pGM1656. We thank the Zeiss Campus Workshop (Carl Zeiss Microlmaging Inc) for assistance with the confocal fluorescence imaging and helpful advice. We thank Rebecca Lee at the University of New Mexico Cancer Center Fluorescence Microscopy Facility (supported as detailed on the webpage: http://hsc.unm.edu/crtc/microscopy/index.shtml) for the expert advice and technical support with the Nuance ${ }^{\mathrm{TM}}$ Multispectral Imaging System. We thank Barbara Hunter (University of Texas Health Science Center at San Antonio) for assistance with scanning and transmission electron microscopy.

This work was supported in part by grants from the Department of Veterans' Affairs (MERIT Award to SAL), the NIDCR, Grant \#DE14318 for the UTHSCSA CO? STAR Program (SMB) and the Biomedical Research Institute of New Mexico (SAL).

\section{Author Details}

1Section of Infectious Diseases, New Mexico Veterans Healthcare System, Albuquerque, NM, USA and 2Division of Infectious Diseases, Department of Medicine, University of New Mexico Health Science Center, Albuquerque, NM USA

Received: 24 February 2009 Accepted: 30 April 2010

Published: 30 April 2010

\section{References}

1. Sivadon P, Peypouquet MF, Doignon F, Aigle M, Crouzet M: Cloning of the multicopy suppressor gene SUR7: evidence for a functional relationship between the yeast actin-binding protein Rvs167 and a putative membranous protein. Yeast 1997, 13(8):747-761.

2. Alvarez FJ, Douglas LM, Rosebrock A, Konopka JB: The Sur7 protein regulates plasma membrane organization and prevents intracellular cell wall growth in Candida albicans. Mol Biol Cell 2008, 19(12):5214-5225.

3. Walther TC, Brickner JH, Aguilar PS, Bernales S, Pantoja C, Walter P: Eisosomes mark static sites of endocytosis. Nature 2006, 439(7079):998-1003.

4. Young ME, Karpova TS, Brugger B, Moschenross DM, Wang GK, Schneiter R, Wieland FT, Cooper JA: The Sur7p family defines novel cortical domains in Saccharomyces cerevisiae affects sphingolipid metabolism and is involved in sporulation. Mol Cell Biol 2002, 22(3):927-934.

5. Alvarez FJ, Konopka JB: Identification of an $\mathrm{N}$-acetylglucosamine transporter that mediates hyphal induction in Candida albicans. $\mathrm{Mol}$ Biol Cell 2007, 18(3):965-975

6. Staab JF, Bradway SD, Fidel PL, Sundstrom P: Adhesive and mammalian transglutaminase substrate properties of Candida albicans Hwp1. Science 1999, 283(5407):1535-1538.

7. Hoyer LL: The ALS gene family of Candida albicans. Trends Microbiol 2001, 9(4):176-180.

8. De Bernardis F, Muhlschlegel FA, Cassone A, Fonzi WA: The pH of the host niche controls gene expression in and virulence of Candida albicans. Infect Immun 1998, 66(7):3317-3325

9. Fonzi WA: PHR1 and PHR2 of Candida albicans encode putative glycosidases required for proper cross-linking of beta-1,3- and beta1,6-glucans. J Bacteriol 1999, 181(22):7070-7079.

10. Ghannoum MA, Spellberg B, Saporito-Irwin SM, Fonzi WA: Reduced virulence of Candida albicans PHR1 mutants. Infect Immun 1995, 63(11):4528-4530.

11. Saporito-Irwin S, Birse C, Sypherd P, Fonzi W: PHR1, a pH-regulated gene of Candida albicans is required for morphogenesis. Mol Cell Biol 1995, 15(2):601-613

12. Nielsen $H$, Engelbrecht J, Brunak S, von Heijne G: Identification of prokaryotic and eukaryotic signal peptides and prediction of their cleavage sites. Protein Eng 1997, 10(1):1-6.

13. Nielsen H, Brunak S, von Heijne G: Machine learning approaches for the prediction of signal peptides and other protein sorting signals. Protein Eng 1999, 12(1):3-9.

14. Lee SA, Wormsley S, Kamoun S, Lee AF, Joiner K, Wong B: An analysis of the Candida albicans genome database for soluble secreted proteins 
using computer-based prediction algorithms. Yeast 2003 20(7):595-610

15. Fradin C, Kretschmar M, Nichterlein T, Gaillardin C, d'Enfert C, Hube B: Stage-specific gene expression of Candida albicans in human blood. Mol Microbiol 2003, 47(6):1523-1543.

16. Albrecht A, Felk A, Pichova I, Naglik JR, Schaller M, de Groot P, Maccallum D, Odds FC, Schafer W, Klis F, et al.: Glycosylphosphatidylinositolanchored proteases of Candida albicans target proteins necessary for both cellular processes and host-pathogen interactions. J Biol Chem 2006, 281(2):688-694.

17. Martchenko M, Alarco A-M, Harcus D, Whiteway M: Superoxide dismutases in Candida albicans: transcriptional regulation and functional characterization of the hyphal-induced SOD5 gene. Mol Biol Cell 2004, 15(2):456-467.

18. Fradin C, De Groot P, MacCallum D, Schaller M, Klis F, Odds FC, Hube B: Granulocytes govern the transcriptional response morphology and proliferation of Candida albicans in human blood. Molecular Microbiology 2005, 56(2):397-415.

19. Hiller E, Heine S, Brunner H, Rupp S: Candida albicans Sun41p a putative glycosidase is involved in morphogenesis cell wall biogenesis and biofilm formation. Eukaryot Cell 2007, 6(11):2056-2065.

20. Norice CT, Smith FJ Jr, Solis N, Filler SG, Mitchell AP: Requirement for Candida albicans SUN41 in biofilm formation and virulence. Eukaryot Cell 2007, 6(11):2046-2055.

21. Firon A, Aubert S, Iraqui I, Guadagnini S, Goyard S, Prevost MC, Janbon G, d'Enfert C: The SUN41 and SUN42 genes are essential for cell separation in Candida albicans. Mol Microbio/ 2007, 66(5):1256-1275.

22. Wilson RB, Davis D, Mitchell AP: Rapid hypothesis testing with Candida albicans through gene disruption with short homology regions. J Bacteriol 1999, 181(6):1868-1874.

23. Wilson RB, Davis D, Enloe BM, Mitchell AP: A recyclable Candida albicans URA3 cassette for PCR product-directed gene disruptions. Yeast 2000 16(1):65-70.

24. Puig S, Perez-Ortin JE: Stress response and expression patterns in wine fermentations of yeast genes induced at the diauxic shift. Yeast 2000, 16(2):139-148.

25. Carlisle PL, Banerjee M, Lazzell A, Monteagudo C, Lopez Ribot JL, Kadosh D: Expression levels of a filament-specific transcriptional regulator are sufficient to determine Candida albicans morphology and virulence. Proc Natl Acad Sci USA 2009, 106(2):599-604.

26. Braun BR, Johnson AD: TUP1, CPH1 and EFG1 make independent contributions to filamentation in Candida albicans. Genetics 2000 155(1):57-67.

27. Brown AJ, Gow NA: Regulatory networks controlling Candida albicans morphogenesis. Trends Microbiol 1999, 7(8):333-338

28. Fu Y, Ibrahim AS, Fonzi W, Zhou X, Ramos CF, Ghannoum MA: Cloning and characterization of a gene (LIP1) which encodes a lipase from the pathogenic yeast Candida albicans. Microbiology 1997, 143:331-340.

29. Chaffin WL, Lopez-Ribot JL, Casanova M, Gozalbo D, Martinez JP: Cell wall and secreted proteins of Candida albicans: identification, function, and expression. Microbiol Mol Biol Rev 1998, 62(1):130-180.

30. Chaffin WL: Candida albicans cell wall proteins. Microbiol Mol Biol ReV 2008, 72(3):495-544

31. Cappelletty D, Eiselstein-McKitrick K: The echinocandins. Pharmacotherapy 2007, 27(3):369-388.

32. Martin R, Hellwig D, Schaub Y, Bauer J, Walther A: Functional analysis of Candida albicans genes whose Saccharomyces cerevisiae homologues are involved in endocytosis. Yeast 2007, 24:511-522.

33. Kaksonen M, Toret CP, Drubin DG: A modular design for the clathrin- and actin-mediated endocytosis machinery. Cell 2005, 123:305-320

34. Douglas LM, Martin SW, Konopka JB: BAR Domain Proteins Rvs 161 and Rvs 167 Contribute to Candida albicans Endocytosis, Morphogenesis, and Virulence. Infection and Immunity 2009, 77(9):4150-4160.

35. Sellam A, Al-Niemi T, Suci P, Nantel A: Characterization and transcriptional profiling of Candida albicans biofilm detachment events. In 9th Candida and Candidiasis: 2008; Jersey City New Jersey, USA American Society for Microbiology; 2008:85-86.

36. Palmer GE, Kelly MN, Sturtevant JE: The Candida albicans Vacuole Is Required for Differentiation and Efficient Macrophage Killing. Eukaryotic Cell 2005, 4(10):1677-1686.
37. Liu H, Kohler J, Fink GR: Suppression of hyphal formation in Candida albicans by mutation of a STE12 homolog. Science 1994 266(5191):1723-1726

38. Ausubel FM, Brent R, Kingston RE, Moore DD, Seidman JG, Smith JA, Struhl K: Current protocols in molecular biology. New York: Wiley; 1993.

39. Gerami-Nejad M, Berman J, Gale CA: Cassettes for PCR-mediated construction of green, yellow and cyan fluorescent protein fusions in Candida albicans. Yeast 2001, 18(9):859-864

40. Bernardo SM, Khalique Z, Kot J, Jones JK, Lee SA: Candida albicans VPS1 contributes to protease secretion, filamentation and biofilm formation. Fungal Genet Biol 2008, 45(6):861-877.

41. Conibear E, Stevens TH: Studying yeast vacuoles. Methods Enzymol 2002, 351:408-432.

42. Crandall M, Edwards JE Jr: Segregation of proteinase-negative mutants from heterozygous Candida albicans. J Gen Microbiol 1987, 133(10):2817-2824

43. Lee SA, Jones J, Khalique Z, Kot J, Alba M, Bernardo S, Seghal A, Wong B: A functional analysis of the Candida albicans homolog of Saccharomyces cerevisiae VPS4. FEMS Yeast Res 2007, 7(6):973-985

44. Rodier MH, Imbert C, Kauffmann-Lacroix C, Daniault G, Jacquemin JL: Immunoglobulins $\mathrm{G}$ could prevent adherence of Candida albicans to polystyrene and extracellular matrix components. J Med Microbiol 2003, 52(Pt 5):373-377.

45. Ramage G, Lopez-Ribot JL: Techniques for antifungal susceptibility testing of Candida albicans biofilms. Methods Mol Med 2005, 118:71-79.

46. Ramage G, Saville SP, Wickes BL, Lopez-Ribot JL: Inhibition of Candida albicans biofilm formation by farnesol, a quorum-sensing molecule. Appl Environ Microbiol 2002, 68(11):5459-5463.

47. Lorenz MC, Bender JA, Fink GR: Transcriptional response of Candida albicans upon internalization by macrophages. Eukaryot Cell 2004, 3(5):1076-1087.

48. Davis D, Wilson RB, Mitchell AP: RIM101-dependent and-independent pathways govern $\mathrm{pH}$ responses in Candida albicans. Mol Cell Biol 2000 20(3):971-978

doi: $10.1186 / 1471-2180-10-133$

Cite this article as: Bernardo and Lee, Candida albicans SUR7 contributes to secretion, biofilm formation, and macrophage killing BMC Microbiology 2010, $10: 133$

\section{Submit your next manuscript to BioMed Centra} and take full advantage of:

- Convenient online submission

- Thorough peer review

- No space constraints or color figure charges

- Immediate publication on acceptance

- Inclusion in PubMed, CAS, Scopus and Google Scholar

- Research which is freely available for redistribution 